\title{
Comparison of the Unilateral and the Bilateral Pedicle Screw Fixation without Using an Interbody Cage: Randomized Clinical Trial
}

\author{
Alexey Lychagin, Vadim Cherepanov, Marina Lipina, Ivan Vyazankin*(i) \\ Department of Traumatology, Orthopaedics and Disaster Surgery, Sechenov First Moscow State Medical University, Moscow, \\ Russia
}

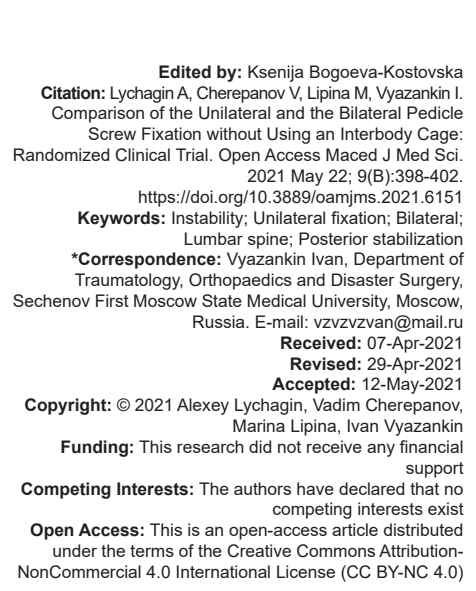

\section{Introduction}

Degenerative diseases of the spine are a widespread problem in world healthcare [1]. Lumbar instability is an important cause of low back pain and has become more prevalent recently [2]. Fusion of the spinal motion segment is a recognized surgical technique in the treatment of degenerative, traumatic diseases of the lumbosacral spine, as well as in the treatment of spinal deformities [3], [4].

The question of choosing between unilateral and bilateral pedicular fixation is of interest to many practicing specialists of our time.

Pedicular screw fixation is traditionally performed bilaterally; however, some authors have recently shown that unilateral pedicle screw fixation is as effective in performing fusion at the level of the lumbar spine as bilateral fixation, and that it allows for shorter operation time as well as shorter duration of hospital stay [5], [6], [7].

\begin{abstract}
Le instability is one of the main causes of low back pain and has become more AIM: The aim of the study was evaluating of the results of unilateral and bilateral pedicle screw fixation without using of an interbody cage. screw fixation of the lumbar spine. Of the 96 patients, 80 patients eventually were included in the study. However, outcomes (scores on the Oswestry disability index [ODI], EQ-5D and visual analogue scale [VAS]) were evaluated in 6-12 months after surgical treatment. All the patients included in this study underwent functional and contro

. The two groups significantly differed in the surgery timing (unilateral $-90.2 \mathrm{~min}$; and bilateral $-129.4 \mathrm{~min}$ ) and blood CONCLUSIONS: Unilateral and bilateral pedicle screw fixation showed similar clinical results, while results in both types of fixation differed in slight manner. However, the duration of surgical treatment and intraoperative blood loss volume proved to be lower for the unilateral fixation group, which indicates that the use of the unilateral fixation can be the choice of performing posterior stabilization at a single-level instability of the spine without using an interbody cage.
\end{abstract}

Some studies conducted with the use of interbody implants have shown good and similar clinical results and indicators of the formation of fusion between unilateral and bilateral pedicle screw fixation [8], [9]. However, none of the researchers studied the issue of using different types of fixation without the use of an implant that replaces the interbody space [10], [11], [12]. Opinions on the effectiveness and choice in favor of a particular technique vary and require further study.

We hypothesize that not only bilateral but also unilateral pedicle screw fixation can be used in the treatment of clinical instability of the lumbar spine with similar clinical results.

The aim of this prospective randomized trial was to compare the clinical outcomes, intraoperative, postoperative, and radiological results of unilateral and bilateral pedicle screw fixation without performing interbody fusion for 12 months after surgery for treatment of instability of the spine. 


\section{Materials and Methods}

The randomized controlled trial sequentially included 96 patients, who underwent surgical treatment in the period from January 2019 to October 2019. Of the 96 patients, 80 patients were included in the study. However, seven patients in the first group and nine patients were lost to follow-up. The patients were randomly divided into two groups, using the computer program Microsoft Excel (version 2019, Microsoft, Redmond, WA) [13]. Patients in Group 1 underwent unilateral pedicle screw fixation $(n=40)$ (Figures 1 and 2), and Group 2 - bilateral pedicle screw fixation $(n=40)$. Treatment results were analyzed for all the patients included into both groups. Clinical outcome and quality of life were primary to assess the study. All patients underwent magnetic resonance imaging (MRI), functional computed tomography (CT) before surgery. The indication for surgical treatment was single level instability of the lumbar spine, which was confirmed by functional CT and MRI. Posner's checklist was used to confirm instability of the lumbar spine [14]. In all patients, conservative treatment
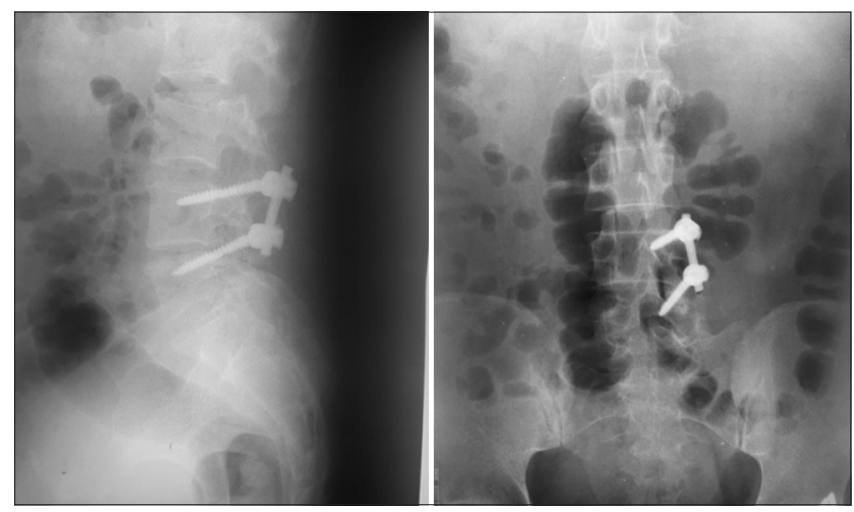

Figure 1: X-ray of a patient from group $i$ (unilateral pedicle screw fixation) on the $1^{\text {st }}$ day after surgery

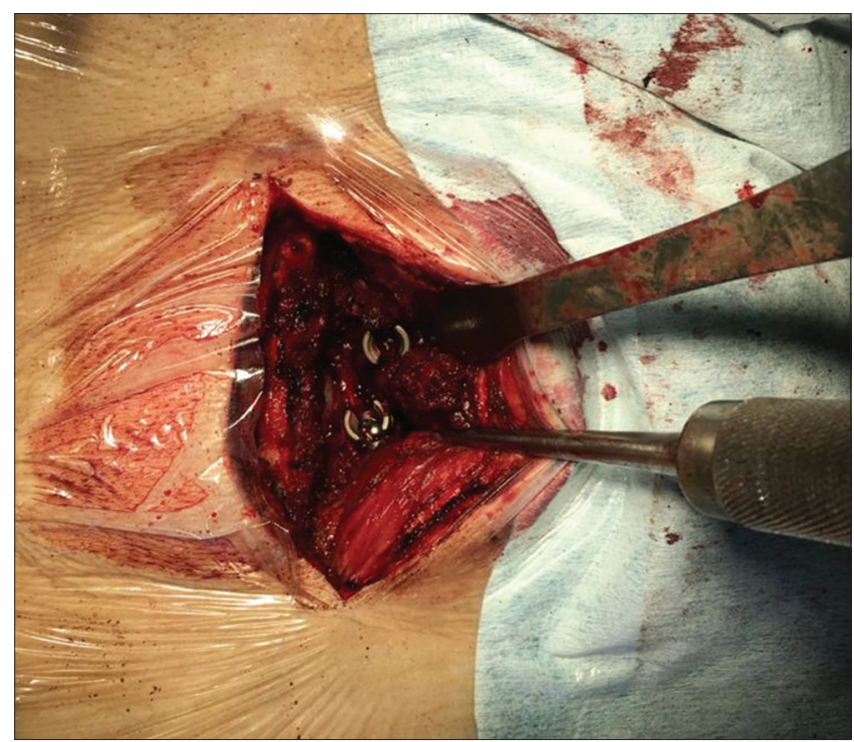

Figure 2: Surgical approach for unilateral pedicle screw fixation lasting at least 6 months before surgery did not lead to a positive result. Inclusion criteria to the trial were as follows:

- Written informed consent of the patient to participate in the study

- $\quad$ Patients with instability of the lumbar spine

- The opportunity for observation during the entire study period (12 months)

- Mental adequacy, ability, willingness to cooperate, and follow the doctor's recommendations.

Our exclusion criteria were as follows:

Confirmed spondylolisthesis

- $\quad$ The refusal of a patient from surgery

- $\quad$ The presence of contraindications to surgery

- $\quad$ Severe forms of diabetes (glycosylated hemoglobin $>9 \%$ )

- Blood diseases (thrombocytopenia, thrombocytopenia, and anemia).

Surgical treatment was performed under endotracheal anesthesia by the open method using the posterior approach on the side that was more symptomatic (based on the patient's complaints, clinical, and physical examination data). An incision was made in the projection of the spinous processes of the treated spinal motion segment. The arches and articular processes of the vertebrae were sharply exposed. The decompressive stage of surgical treatment was completed. After decompression of neural structures under $\mathrm{C}$-arm control, unilateral pedicle screw fixation was performed for Group I with a bone graft at the facet joint, while bilateral pedicle screw fixation with a bone graft at the facet joints was performed for Group II with open surgical approach from the contralateral side. The bone graft was made from the resected bone during decompressive stage.

The wound was treated with antiseptic solutions and layers of sutures with aseptic treatment. All patients were operated by one surgeon.

Intraoperative evaluation of the results included: Time of surgery and volume of blood loss during surgery. All patients underwent a course of standard rehabilitation treatment. Clinical and functional results were assessed using visual analog scale (VAS) for back and leg pain, EQ-5D, and Oswestry Disability Index (ODI): Before surgery, and then 3,6 , and 12 months after surgery. Control CT in 12 months after surgery was assessed by roentgenologist. Glassman classification was used to rate posterior spinal fusion [15]: No fusion (Grade 1), partial unilateral fusion (Grade 2), partial bilateral fusion (Grade 3), solid unilateral fusion (Grade 4), and solid bilateral fusion (Grade 5). Completed posterior lumbar fusion was considered as Glassman Grade 4 and Glassman Grade 5. identifier).

Registration: NCT04415814 (ClinicalTrials.gov 


\section{Statistical data assessment}

Statistica 10.0 software for Windows (StatSoft Inc., USA) was used for statistical analysis of the results. Quantitative variables were described using standard methods of variation statistics, where the arithmetic mean (M) and standard deviation were applied ( $\delta$ ). Average values are presented as $M \pm \delta$. Qualitative variables were described as absolute and relative frequency ratios. Differences were considered significant at $p<0.05$. Methods of statistical analysis were used to evaluate the results: Student's t-test.

Ethics committee approval was obtained to conduct the study. The study was carried out in accordance with ethical standards.

All patients who took part in the study gave their informed consent before their inclusion in the study.

\section{Results}

Based on the results of the pre-operative examinations, all patients were diagnosed with single level instability in the spinal motion segment of the lumbosacral spine.

In all studied patients, 12 months after surgery, completed posterior spinal fusion was detected and recorded on a control CT, which was rated by Glassman.

The average follow-up period was $15.2 \pm$ 3.7 months, and the average age of patients was $57.2 \pm$ 17.1 years. Both groups were comparable in age, gender (male to female ratio 17:23 [1 $1^{\text {st }}$ group] and 19:21 [ $2^{\text {nd }}$ group]) $(p>0.05)$, and the operated segments L4-L5: 34 patients (Group 1) and 35 patients (Group 2); and L5-S1: Six patients (Group 1) and five patients (Group 2), ( $p>0.05$ ).

According to intraoperative estimates, the time of surgical intervention for the $1^{\text {st }}$ group (90.2 $\mathrm{min}$ ) was significantly shorter than for the $2^{\text {nd }}$ group (129.4 min; $p<0.05$ ), and the average blood loss for the $1^{\text {st }}$ group (152.7 ml.) was lower than for Group $2(230.1 \mathrm{ml}$., $p<0.05$; Table 1). Regarding clinical results, the ODI index significantly improved within 1 year after surgery in both groups (from $69.5 \%$ to $23.8 \%$ for Group 1 , and from $70.1 \%$ to $23.2 \%$ for Group 2, p < 0.05 ).

Table 1: Characteristics of the observed patients groups

\begin{tabular}{lllll}
\hline Groups & Age, years & $\begin{array}{l}\text { Time of } \\
\text { observation, } \\
\text { months }\end{array}$ & $\begin{array}{l}\text { Timing of } \\
\text { operation, } \\
\text { minutes }\end{array}$ & $\begin{array}{l}\text { Intraoperative } \\
\text { blood loss, ml }\end{array}$ \\
\hline $\begin{array}{l}\text { Group I (unilateral } \\
\text { fixation) }\end{array}$ & $(57.1 \pm 17.2)$ & $(15.5 \pm 2.1)$ & $(90.2 \pm 28.7)$ & $(152.7 \pm 38.4)$ \\
$\begin{array}{l}\text { Group Il (bilateral } \\
\text { fixation) }\end{array}$ & $(56.8 \pm 16.8)^{*}$ & $(14.9 \pm 2.3)^{*}$ & $(129.4 \pm 31.2)^{\star *}$ & $(230.1 \pm 36.7)^{\star *}$ \\
\hline $\begin{array}{l}\left({ }^{*}\right): \text { No significant differences between groups, } p>0.05,\left({ }^{*}\right) \text { : Differences between groups are significant, } \\
p<0.05,{ }^{1} \text { ml: Milliliter. }\end{array}$ &
\end{tabular}

The EQ-5D index in patients of Group 1 was 0.091 and 0.041 in Group 2; a year after surgery, the index value was 0.835 and 0.799 , respectively $(p<0.05)$. In each group the indicators significantly improved 1 year after surgery compared to the clinical state before surgery. The VAS score for back pain significantly improved 6 months after surgery (from $84 \mathrm{~mm}$ to $22 \mathrm{~mm}$ for Group 1, and from $82 \mathrm{~mm}$ to $23 \mathrm{~mm}$ for Group 2, $\mathrm{p}<0.05$ ), and the VAS score for leg pain also improved significantly (from $76 \mathrm{~mm}$ to $18 \mathrm{~mm}$ for Group 1, and from $75 \mathrm{~mm}$ to $19 \mathrm{~mm}$ for Group $2, p<0.05$ ). There were no statistically significant differences between the groups ( $p>0.05$, Figure 3 ).

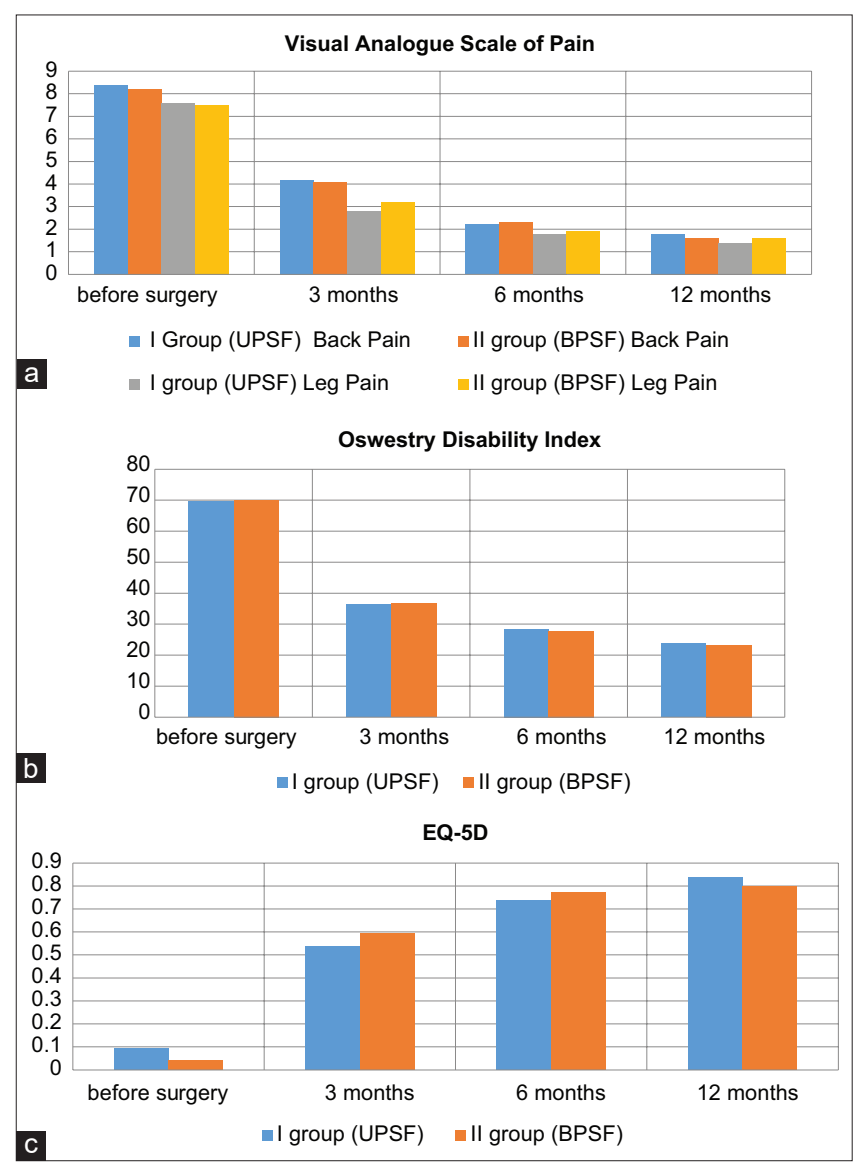

Figure 3: Dynamics of clinical and functional indicators: (a) Visual analog scale; (b) EQ-5D; (c) Oswestry Disability Index; $p<0.05$

Of all 80 patients, one case of complications associated with the operation with the performance of intervention due to infectious postoperative complications was identified. The patient underwent repeated surgery in the amount of primary surgical treatment of the wound with excision of the post-operative scar, removal of suture material, and treatment of the wound with antiseptic solutions. During revision surgery, it was decided to keep the pedicle screw fixation system. During 1 year follow-up after revision surgery, there was no difference in the clinical assessment with other included patients.

\section{Discussion}

We hypothesized that not only bilateral but also unilateral pedicle screw fixation can be used in the 
treatment of clinical instability of the lumbar spine with similar clinical results.

Despite the existence of numerous studies evaluating the results of unilateral and bilateral pedicle screw fixation in the formation of lumbar fusion, data on assessing the possibility of using pedicle screw fixation without the introduction of an interbody implant are quite rare and controversial, and the conclusions of many of these studies contradict each other in terms of identifying which fixation method is more effective in the treatment of instability of the lumbar spine [16], [17], [18].

Fernández-Fairen et al. compared unilateral and bilateral pedicle screw fixation in 82 patients with high-grade spondylolisthesis. The authors claim similar clinical results in the two groups of patients, with reduced duration of surgical treatment, reduced blood loss, and lower cost of implants [19].

Recently, several systematic reviews have been performed based on meta-analyses [20], [21], which can provide information that can help an operating surgeon. However, the conclusions of most of the studies are inconsistent and oftentimes contradictory. For example, a meta-analysis by Lu et al. [22] did not reveal any obvious differences between the two methods of fixation of the lumbar spine in terms of functional parameters, length of hospital stay, rate of fusion, and the frequency of complications.

In addition, unilateral pedicle screw fixation has an advantage over bilateral fixation in terms of the duration of surgery and blood loss, but it increases the risk of interbody cage migration. Based on the above findings, the researchers concluded that unilateral fixation is recommended as the optimal fixation method in the formation of lumbar fusion.

Nevertheless, according to some studies, unilateral fixation causes adverse effects due to the asymmetry of the spine and reduced stability of the operated segment; however, it should be noted that there were no differences in the rate of fusion formation, the risk of revision intervention or post-operative complications in comparison with bilateral pedicle screw fixation [23]. Moreover, most of the available works describe the use of unilateral transpedicular fixation exclusively in the surgical treatment of one- or two-level degenerative diseases of the lumbar spine [5], [24].

Some studies have shown that unilateral pedicle screw fixation significantly reduces surgery time and blood loss compared to bilateral pedicle screw fixation during decompression and stabilization operations on the lumbar spine, and less trauma associated with surgical access performed on one side was noted [25], [26], [27].

Our study and the results obtained allowed us to show the absence of significant differences in the clinical and functional results of both types of surgical treatment, as well as to confirm the available data on the low volume of intraoperative blood loss and the shorter duration of the operation. It is useful to extend the follow-up period and continue further trials on the use of unilateral pedicle screw fixation in the treatment of lumbar spine instability.

\section{Conclusions}

Unilateral and bilateral pedicle screw fixation showed similar clinical and functional results. However, the timing of surgical treatment, the number of implants used, as well as intraoperative blood loss are lower in the unilateral fixation group, which indicates that the use of unilateral fixation can be the choice of performing posterior stabilization in case of a single-level instability of the spine without using an interbody implant.

\section{References}

1. Chan AY, Lien BV, Choi EH, Chan AK, Hanna G, Lopez AM, et al. Back pain outcomes after minimally invasive anterior lumbar interbody fusion: A systematic review. Neurosurg Focus. 2020;49(3):E3. https://doi.org/10.3171/2020.6.focus20385

PMid:32871569

2. Inoue D, Shigematsu H, Nakagawa $Y$, Takeshima T, Tanaka $Y$, The influence of posture on instability evaluation using flexionextension X-ray imaging in lumbar spondylolisthesis. Asian Spine J. 2020 Sep 22. https://doi.org/10.31616/asj.2020.0124 PMid:32951403

3. Lee $\mathrm{KH}$, Yue WM, Yeo W, Soeharno H, Tan SB. Clinical and radiological outcomes of open versus minimally invasive transforaminal lumbar interbody fusion. Eur Spine J. 2012;21(11):2265-70. https://doi.org/10.1007/ s00586-012-2281-4

PMid:22453894

4. Liu H, Xu Y, Yang SD, Wang T, Wang H, Liu FY, et al. Unilateral versus bilateral pedicle screw fixation with posterior lumbar interbody fusion for lumbar degenerative diseases: A metaanalysis. Medicine (Baltimore). 2017;96(21):e6882. https://doi. org/10.1097/md.0000000000006882

PMid:28538379

5. Muthu S, Chellamuthu G. How safe is unilateral pedicle screw fixation in lumbar fusion surgery for management of 2-level lumbar degenerative disorders compared with bilateral pedicle screw fixation? Meta-analysis of randomized controlled trials. World Neurosurg. 2020;140:357-68. https://doi.org/10.1016/j. wneu.2020.05.078

PMid:32428724

6. Huang P, Wang Y, Xu J, Xiao B, Liu J, Che L, et al. Minimally invasive unilateral pedicle screws and a translaminar facet screw fixation and interbody fusion for treatment of singlesegment lower lumbar vertebral disease: Surgical technique and preliminary clinical results. J Orthop Surg Res. 2017;12(1):117. https://doi.org/10.1186/s13018-017-0606-z PMid:28728587

7. Du JY, Kiely PD, Al Maaieh M, Aichmair A, Huang RC. Lateral lumbar interbody fusion with unilateral pedicle screw fixation 
for the treatment of adjacent segment disease: A preliminary report. J Spine Surg. 2017;3(3):330-7. https://doi.org/10.21037/ jss.2017.06.17

PMid:29057340

8. Liu YY, Xiao J, Jin HJ Wang Z, Yin X, Liu MY, et al. Comparison of unilateral and bilateral polymethylmethacrylate-augmented cannulated pedicle screw fixation for the management of lumbar spondylolisthesis with osteoporosis. J Orthop Surg Res. 2020;15(1):446. https://doi.org/10.1186/s13018-020-01975-1 PMid:32993741

9. Joseph JR, Smith BW, La Marca F, Park P. Comparison of complication rates of minimally invasive transforaminal lumbar interbody fusion and lateral lumbar interbody fusion: A systematic review of the literature. Neurosurg Focus. 2015;39(4):E4. https://doi.org/10.3171/2015.7.focus15278 PMid:26424344

10. Luo P, Shao RX, Wu AM, Xu HZ, Chi YL, Lin Y. Transforaminal lumbar interbody fusion with unilateral pedicle screw and contralateral percutaneous transfacet screw fixation for the treatment of lumbar degenerative disorders. Turk Neurosurg. 2016;26(5):763-70. https://doi.org/10.5137/1019-5149. jtn.12450-14.1 PMid:27438624

11. Soriano-Sánchez JA, Quillo-Olvera J, Soriano-Solis S, SorianoLopez ME, Covarrubias-Rosas CA, Quillo-Reséndiz J, et al. A prospective clinical study comparing MI-TLIF with unilateral versus bilateral transpedicular fixation in low grade lumbar spondylolisthesis. J Spine Surg. 2017;3(1):16-22. https://doi. org/10.21037/jss.2017.03.04 PMid:28435913

12. Duncan JW, Bailey RA. An analysis of fusion cage migration in unilateral and bilateral fixation with transforaminal lumbar interbody fusion. Eur Spine J. 2013;22(2):439-45. https://doi. org/10.1007/s00586-012-2458-x PMid:22878377

13. Randelli $P$, Arrigoni $P$, Lubowitz JH, Cabitza $P$, Denti M. Randomization procedures in orthopaedic trials. Arthroscopy. 2008;24(7):834-38. https://doi.org/10.1016/j.arthro.2008.01.011 PMid:18589273

14. Posner I, White AA $3^{\text {rd }}$, Edwards WT, Hayes WC. A biomechanical analysis of the clinical stability of the lumbar and lumbosacral spine. Spine (Phila Pa 1976). 1982;7(4):374-89. https://doi. org/10.1097/00007632-198207000-00008 PMid:7135070

15. Glassman SD, Dimar JR, Carreon LY, Campbell MJ, Puno RM, Johnson JR. Initial fusion rates with recombinant human bone morphogenetic protein-2/compression resistant matrix and a hydroxyapatite and tricalcium phosphate/ collagen carrier in posterolateral spinal fusion. Spine (Phila $\mathrm{Pa}$ 1976). 2005;30(15):1694-8. https://doi.org/10.1097/01. brs.0000172157.39513.80 PMid:16094268

16. Li X, Lv C, Yan T. Unilateral versus bilateral pedicle screw fixation for degenerative lumbar diseases: A meta-analysis of 10 randomized controlled trials. Med Sci Monit. 2015;21:782-90. https://doi.org/10.12659/msm.892593 PMid:25774950

17. Shen X, Wang L, Zhang H, Gu X, Gu G, He S. Radiographic analysis of single level minimally invasive transforaminal lumbar interbody fusion (MI-TLIF) with unilateral pedicle screw fixation for lumbar degenerative diseases. Clin Spine Surg. 2016;29(1):E1-8

PMid:24189485

18. Zhao Y, Yang S, Ding W. Unilateral versus bilateral pedicle screw fixation in lumbar fusion: A systematic review of overlapping meta-analyses. PLoS One. 2019;14(12):e0226848. https://doi. org/10.1371/journal.pone.0226848

PMid:31860651

19. Fernández-Fairen $M$, Sala $P$, Ramírez $H$, Gil J. A prospective randomized study of unilateral versus bilateral instrumented posterolateral lumbar fusion in degenerative spondylolisthesis. Spine (Phila Pa 1976). 2007;32(4):395-401. https://doi. org/10.1097/01.brs.0000255023.56466.44

PMid:17304127

20. Ren $C$, Qin R, Sun P, Wang P. Effectiveness and safety of unilateral pedicle screw fixation in transforaminal lumbar interbody fusion (TLIF): A systematic review and meta-analysis. Arch Orthop Trauma Surg. 2017;137(4):441-50. https://doi. org/10.1007/s00402-017-2641-y

PMid:28168642

21. Phan K, Leung V, Scherman DB, Tan AR, Rao PJ, Mobbs RJ. Bilateral versus unilateral instrumentation in spinal surgery: Systematic review and trial sequential analysis of prospective studies. J Clin Neurosci. 2016;30:15-23. https://doi. org/10.1016/j.jocn.2016.01.013 PMid:27068653

22. Lu P, Pan T, Dai T, Chen G, Shi KQ. Is unilateral pedicle screw fixation superior than bilateral pedicle screw fixation for lumbar degenerative diseases: A meta-analysis. J Orthop Surg Res. 2018;13(1):296. https://doi.org/10.1186/s13018-018-1004-x PMid:30466462

23. Liu F, Feng Z, Zhou X, Liang Y, Jiang C, Li X, et al. Unilateral versus bilateral pedicle screw fixation in transforaminal lumbar interbody fusion: A monocentric study of 215 patients with a minimum of 4-year follow-up. Clin Spine Surg. 2017;30(6):E77683. https://doi.org/10.1097/bsd.0000000000000416 PMid:27404853

24. Li J, Wang W, Zuo R, Zhou Y. Biomechanical stability before and after graft fusion with unilateral and bilateral pedicle screw fixation: Finite element study. World Neurosurg. 2019;123:e22834. https://doi.org/10.1016/j.wneu.2018.11.141

PMid:30481621

25. Fukushima M, Oshima $\mathrm{Y}$, Yuzawa $\mathrm{Y}$, Tanaka S, Inanami $\mathrm{H}$. Clinical and radiographic analysis of unilateral versus bilateral instrumented one-level lateral lumbar interbody fusion. Sci Rep. 2020;10(1):3105. https://doi.org/10.1038/ s41598-020-59706-9 PMid:32080245

26. Molinari RW, Saleh A, Molinari R Jr., Hermsmeyer J, Dettori JR. Unilateral versus bilateral instrumentation in spinal surgery: A systematic review. Glob Spine J. 2015;5(3):185-94. https:// doi.org/10.1055/s-0035-1552986

PMid:26131385

27. Gao ZY, Qin J, Kang J, Song H, He XJ, Li HP, et al. Unilateral versus bilateral pedicle screw fixation in minimally invasive transforaminal lumbar interbody fusion (MIS-TLIF): A meta analysis. Zhongguo Gu Shang. 2016;29(10):954-62. https://doi. org/10.1186/1471-2482-14-87

PMid:29285916 